\title{
Sugar-sweetened beverages as the new tobacco: examining a proposed tax policy through a Canadian social justice lens
}

\author{
Natalie D. Riediger PhD, Andrea E. Bombak PhD
}

Cite as: CMAJ 2018 March 19;190:E327-30. doi: 10.1503/cmaj.170379

CMAJ Podcasts: author interview at https://soundcloud.com/cmajpodcasts/170379-ana

I

ntake of sugar-sweetened beverages is consistently, positively associated with obesity. ${ }^{1}$ A much-discussed policy lever to address obesity is taxation of such beverages. The Canadian Diabetes Association, ${ }^{2}$ Heart and Stroke Foundation ${ }^{3}$ and World Health Organization (WHO $)^{4}$ have endorsed taxation on sugar-sweetened beverages, although no Canadian jurisdictions have yet implemented such a tax. Proponents of this taxation often point to the effectiveness of taxation on tobacco as a policy to reduce smoking rates at the population level and consider the effects of tobacco taxation to be a useful benchmark for predicting the behavioural and health effects of taxes on sugar-sweetened beverages. ${ }^{5}$ However, taxation on tobacco has not led to equal benefits for all strata of society. Although the WHO suggests it is a "myth" that taxes on sugar-sweetened beverages have adverse impacts on low-income populations, the organization cites no evidence to support this assertion. ${ }^{4}$ Many public health policies have unintended consequences for some groups and it is important to consider this when implementing new policies.

Both intake of sugar-sweetened beverages and prevalence of obesity and diabetes are substantially higher among Indigenous populations and those of low socioeconomic status in Canada. ${ }^{6-8}$ Therefore, for taxation of sugar-sweetened beverages to be effective as a measure of population health, it must affect consumption in these populations. We present a critical, social justice-oriented analysis, focusing on the potential effects of sugar taxation on equity, stigma and First Nations populations, drawing comparisons with recognized effects of tobacco taxation.

\section{Equity}

What can taxation on tobacco teach us about equity of impact?

Taxation, along with other demand and supply measures, has proven effective at reducing overall population smoking rates. In Canada, the prevalence of smoking decreased from $68.9 \%$ in 1950 to $18.6 \%$ in 2011 among men and from $38.2 \%$ to $15.4 \%$

\section{KEY POINTS}

- Lessons learned from taxation on tobacco should be considered in discussions on taxation of sugar-sweetened beverages.

- Taxation on tobacco has contributed to widening socioeconomic inequalities in smoking.

- Taxes on sugar-sweetened beverages may exacerbate stigma regarding obesity, just as taxes on tobacco contributed to stigma about smoking.

- First Nations communities need to be considered in discussions about tax policy for sugar-sweetened beverages.

among women. ${ }^{9}$ However, these gains have not affected all people equally. For example, smoking has decreased to a much lesser extent among those with lower levels of education, which has resulted in widening inequalities over time. ${ }^{9}$ The prevalence of smoking among Canadian men with less than secondary education was $42.5 \%$ in 2011 . Cigarette consumption is also substantially higher and quit rates much lower among smokers from low compared with high socioeconomic groups. ${ }^{10}$ The large overall reduction in population smoking prevalence was driven by high reductions in groups with higher socioeconomic status. Even taxation, an economic measure with higher impact on lower-income groups, effects behaviour change less well among the economically disadvantaged. Worth noting is that tobacco taxes were introduced before the development of socioeconomic statusbased differences in smoking rates for women. ${ }^{9}$ The epidemiology of intake of sugar-sweetened beverages already shows a socioeconomic gradient despite beverage taxes being a new phenomenon, ${ }^{7,8}$ which underscores the need for public health measures that will work for the socioeconomically disadvantaged if reducing intake at the population level is the goal.

\section{Is there evidence to support taxation of sugar-} sweetened beverages in disadvantaged populations? There is little evidence to show that taxation of sugar-sweetened beverages is effective at reducing their intake among people of 
lower socioeconomic status. The first study to evaluate changes in beverage intake following the start of a tax on sugarsweetened beverages in Berkley, California, did show that intake of sugar-sweetened beverages was reduced in "low-income" neighbourhoods in the city compared with neighbouring jurisdictions that did not have the tax. ${ }^{11}$ However, the census tracts selected for this study had median incomes of US\$59000 in Berkeley, and $\$ 46000$ in Oakland and $\$ 52000$ in San Francisco, the two comparison populations. These census tracts could hardly be classified as "low-income" or "vulnerable," as described by the study authors. Other important biases include substantially higher proportions of Hispanic participants, substantially lower education levels and greater likelihood to complete the survey in Spanish in comparison samples. ${ }^{11}$

An observational study showed that Mexico experienced a decline in intake of sugar-sweetened beverages after the introduction of a tax in 2014, including among low-income populations. ${ }^{12}$ The robustness of this evidence to support beverage taxation is in question, although it is often referenced in this context.

First, the study's authors noted that "causality cannot be established," given that there is not a comparison population. In Canada, sales of regular soft drinks, fruit drinks and $100 \%$ fruit juice were 27\% lower in 2015 compared with 2004 levels, which occurred without a similar tax. ${ }^{3}$

Second, $37 \%$ of the Mexican population were not represented in the study; those not represented included homeless people and populations of cities with fewer than 50000 residents; that is, rural populations, which disproportionately include Indigenous people and those of low socioeconomic status.

Third, the authors of the research reported a mean decrease in purchases of taxed beverages by $12 \mathrm{~mL} /$ capita/ day; however, intake of sugar-sweetened beverages is not normally distributed in the population and the findings cannot tell us about trends among high consumers. With respect to health risks, the impact of a beverage tax on high consumers of sugarsweetened beverages is considerably more important than on those who reduce their consumption from three to two cans of cola per month (which was the average monthly decline reported).

Fourth, the Mexican population had one of the highest intakes of sugar-sweetened beverages globally before the introduction of a tax; it is likely that intake had already reached a threshold. Moreover, the study's authors noted that intake of sugar-sweetened beverages was declining before the introduction of the tax, particularly among households of high socioeconomic status. Lastly, and possibly most importantly, we must exercise caution in extrapolating results from Mexico to the Canadian situation, as Mexico's population has a substantially different social and economic structure.

Economic simulation modelling frequently assumes that compared with other populations, people of lower socioeconomic status would benefit disproportionally because of their existing high intake of sugar-sweetened beverages, greater sensitivity to price increases (higher price elasticity) and higher burden of obesity-related health outcomes. ${ }^{13}$ However, many other factors influence the socioculturally complex decisions regarding food choices, which are not morally neutral and may follow different patterns of socialization. ${ }^{14,15}$ Proponents of taxation of sugar-sweetened beverages argue that tax revenues fund a larger suite of programs and policies, including food subsidies, which makes them inherently equitable. However, excise taxes go toward general revenue without a mechanism to trace their subsequent use in program spending, and there is no evidence that individuals who are disproportionately affected by a tax on sugar-sweetened beverages would benefit from any of the proposed "funded" policies.

\section{Stigma}

The current public health approach to smoking assumes, among other things, that once Big Tobacco's unscrupulous marketing tactics and the health effects of smoking are demonstrated, people will either quit or decide not to smoke through a sense of personal responsibility. ${ }^{16}$ This has strong moralistic undercurrents, ignores the context of the smoker and pleasure derived from smoking, and may stigmatize some already-marginalized populations. ${ }^{16,17}$ For example, a recent qualitative study found that smokers in low-income groups in New Zealand felt victimized by increases in tobacco taxes that pressured people to quit smoking in the face of inadequate provision of cessation supports. ${ }^{18} \mathrm{~A}$ qualitative study found that socially marginalized Canadian youth who smoke - but not privileged youth who smoke - had feelings of shame about their behaviour. ${ }^{19}$

Taxation on sugar-sweetened beverages is positioned as a strategy to reduce obesity. ${ }^{4}$ Like smoking, obesity is associated with pronounced stigma, in part because it is framed as a matter of personal responsibility. ${ }^{20}$ As a result of personal responsibility framing, excess weight can become conflated with laziness and sloth, and public health measures that are framed in this way may exacerbate well-known physical and mental health-damaging effects of obesity stigma. ${ }^{20}$ Recent "anti-soda" public health campaigns, including the "Berkeley v. Big Soda" campaign, have been criticized as stigmatizing for individuals with low income or obesity. ${ }^{21}$

Furthermore, a sweetened beverage tax aimed only at regular soft drinks may carry classist and racist overtones that could exacerbate stigma directed at already-marginalized groups. For example, it is interesting to note which beverages are discussed as "tax targets." Sweetened coffee sales increased 579\% in Canada from 2004 to $2015 ;^{3}$ coffee was already the most frequently consumed beverage, after water, in 2004.22 Taxing (nonbottled) sweetened coffee is not currently included in any tax on sugar-sweetened beverages; nor has it been proposed. US data indicate that consumption of store-purchased sweetened coffee and tea intake is significantly higher in regions of higher socioeconomic categorization and in those in which a higher proportion of the population identifies as white. ${ }^{23}$ In other words, economically advantaged people may continue to drink their frappuccino, untaxed, while less wealthy people are taxed for their cola, despite similar added sugar content. 


\section{Effects of taxation policies on Indigenous populations}

Canada, as a country, has so far failed to develop effective and acceptable strategies in collaboration with First Nations communities to address smoking; smoking prevalence among First Nations is triple that of settler populations. ${ }^{24}$ In some communities, the prevalence of current smoking is increasing. ${ }^{25}$ For the federal government, taxing tobacco is the primary strategy to reduce tobacco use. However, tobacco taxes are complicated by jurisdictional differences related to taxation on reserve. First Nations communities have the authority to tax tobacco products, but less than $2 \%$ of bands tax tobacco. ${ }^{26}$ Tobacco has cultural significance for First Nations, but it is also an issue of sovereignty; it is one of the few areas in which First Nations communities can exercise control independent of the federal government. The lack of tobacco taxes on reserve has been used to blame First Nations communities for the illicit trade of contraband cigarettes in Canada. ${ }^{27}$ Such finger pointing further undermines harmonious collaboration between First Nations communities and other peoples - driving a lack of respect and partnership with First Nations people in policy development - and it contributes to further stigmatization for an already-marginalized population.

In light of these observations, it is important to consider the potential that a tax on sugar-sweetened beverages may negatively affect reconciliation between Indigenous and other peoples in Canada. Water quality on First Nations reserves remains an intractable problem in Canada. As of August 2017, there were 103 long-term drinking water advisories in First Nations communities, ${ }^{28}$ some in place for more than a decade. This number does not include the many communities with intermittent drinking water advisories or potable-but-not-palatable water. Many remote communities rely on purchased beverages for hydration. A $4 \mathrm{~L}$ jug of milk costs more than Can\$10, even after subsidies through Nutrition North Canada (a federal food subsidy program for remote Northern communities, which aims to improve access to perishable foods). ${ }^{29}$ Communities frequently rely on sugarsweetened beverages for hydration, as these beverage types are not perishable. Because of ongoing water safety issues, First Nations people are likely to have legitimate concerns over policies that aim to increase water consumption by making other beverages more expensive.

Contributing to dietary patterns among First Nations people and the associated high rates of diabetes are factors related to colonialism, which include historical loss of land, introduction of market foods, and hunger at residential schools, among others. ${ }^{30}$ Indeed, concerns related to colonialism and taxation on sugar-sweetened beverages are magnified when agricultural subsidies and the historical context of farming are taken into consideration. This occurs because in Canada, sugar-sweetened beverages are most commonly sweetened with high-fructose corn syrup; ${ }^{31}$ corn growers therefore benefit from government subsidies, and farmers may have inherited family farms that were established on free land for settlers at the expense of limiting land for Indigenous people. These ties between sugar and colonialism, formed by bitter history, may cast any proposed tax on sugar-sweetened beverages as part of ongoing subjugation of Indigenous peoples and the ahistorical, depoliticized and paternalistic concern of more privileged groups. Such concerns must be taken into account when formulating a policy that may well affect Indigenous peoples negatively and disproportionately. Indigenous communities must be engaged in the policy process. It is crucially important to incorporate insights from communities when developing policies that affect those communities.

\section{Conclusion}

Proponents of a tax on sugar-sweetened beverages are quick to emphasize positive aspects of a tobacco tax; however, a thorough comparison analysis reveals other lessons about exacerbation of inequity and stigma, including racial stigma, in already-marginalized populations. True economic and health reform will require more thoughtful policies than trying to "nudge" people to make "more appropriate" choices.

\section{References}

1. Malik VS, Schulze MB, Hu FB. Intake of sugar-sweetened beverages and weight gain: a systematic review. Am J Clin Nutr 2006;84:274-88.

2. Diabetes Canada's position on sugars. Diabetes Canada; 2016. Available: www. diabetes.ca/about-cda/public-policy-position-statements/sugars (accessed 2016 Dec. 8).

3. Jones AC, Veerman JL, Hammond D. The health and economic impact of a tax on sugary drinks in Canada. 2017. Available: www.heartandstroke.ca/-/media/pdf -files/canada/media-centre/health-economic-impact-sugary-drink-tax-in-canada-en (accessed 2016 Dec. 8).

4. Fiscal policies for diet and prevention of noncommunicable diseases. World Health Organization technical meeting report; 2015 May 5-6; Geneva, Switzerland. Available: http://apps.who.int/iris/bitstream/10665/250131/1/9789241511247-eng.pdf?ua=1 (accessed 2016 Nov. 30).

5. Blecher E. Taxes on tobacco, alcohol and sugar-sweetened beverages: Linkages and lessons learned. Soc Sci Med 2015;136-137:175-9.

6. $\mathrm{Ng} \mathrm{C}$, Corey PN, Young TK. Socio-economic patterns of obesity among Aboriginal and non-Aboriginal Canadians. Can J Public Health 2011;102:264-8.

7. Nikpartow N, Danyliw AD, Whiting SJ, et al. Beverage consumption patterns of Canadian adults aged 19 to 65 years. Public Health Nutr 2012;15:2175-84.

8. Langlois KA, Findlay LC, Kohen DE. Dietary habits of Aboriginal children. Health Rep 2013;24:3-7.

9. Corsi DJ, Boyle MH, Lear SA, et al. Trends in smoking in Canada from 1950 to 2011: progression of the tobacco epidemic according to socioeconomic status and geography. Cancer Causes Control 2014;25:45-57.

10. Reid JL, Hammond D, Driezen P. Socioeconomic status and smoking in Canada 1999-2006: Has there been any progress on disparities in tobacco use? Can J Public Health 2010;101:73-8.

11. Falbe J, Thompson HR, Becker CM, et al. Impact of the Berkeley excise tax on sugar-sweetened beverage consumption. Am J Public Health 2016;106:1865-71.

12. Colchero MA, Popkin BM, Rivera JA, et al. Beverage purchases from stores in Mexico under the excise tax on sugar sweetened beverages: observational study. BMJ 2016;352:h6704.

13. Backholer K, Sarink D, Beauchamp A, et al. The impact of a tax on sugarsweetened beverages according to socio-economic position: a systematic review of the evidence. Public Health Nutr 2016;19:3070-84.

14. Kirkland A. The environmental account of obesity: a case for feminist skepticism. Signs (Chic) 2011;36:463-86.

15. McPhail D, Chapman GE, Beagan BL. The rural and the rotund? A critical interpretation of food deserts and rural adolescent obesity in the Canadian context. Health Place 2013;22:132-9.

16. Bell K. Tobacco control, harm reduction and the problem of pleasure. Drugs Alcohol Today 2013;13:111-8.

17. Graham H. Smoking, stigma and social class. J Soc Policy 2012;41:83-99. 
18. Hoek J, Smith K. A qualitative analysis of low income smokers' responses to tobacco excise tax increases. Int J Drug Policy 2016;37:82-9.

19. Frohlich KL, Mykhalovskiy E, Poland BD, et al. Creating the socially marginalised youth smoker: the role of tobacco control. Sociol Health Illn 2012;34:978-93.

20. Puhl RM, Heuer CA. Obesity stigma: Important considerations for public health. Am J Public Health 2010;100:1019-28.

21. Packer M. Soda policies and social anxieties. Berkeley J Sociol 2016. Available: http://berkeleyjournal.org/2016/05/soda-policies-and-social-anxieties/ (accessed 2017 May 16).

22. Beverage consumption of Canadian adults, findings. Ottawa: Statistics Canada; 2015 [updated 2015 July 17]. Available: www.statcan.gc.ca/pub/82-003-x/2008004/ article/10716/6500244-eng.htm (accessed 2017 Apr. 3).

23. Park S, McGuire LC, Galuska DA. Regional differences in sugar-sweetened beverage intake among US adults. J Acad Nutr Diet 2015;115:1996-2002.

24. First Nations \& Inuit Health: tobacco [updated 2016 Mar. 3]. Ottawa: Health Canada. Available: www.hc-sc.gc.ca/fniah-spnia/substan/tobac-tabac/index-eng.php\#facts (accessed 2017 Apr. 17).

25. Riediger ND, Lukianchuk V, Lix LM, et al. Between a rock and a hard place: smoking trends in a Manitoba First Nation. Can J Public Health 2015;106:e184-8.

26. Wardman AE, Khan NA. Registered Indians and tobacco taxation: a culturally appropriate strategy? Can J Public Health 2005;96:451-3.

27. McLaughlin P. Contraband cigarettes becoming a national norm. CMAJ 2007; 176:1567-8.

28. Drinking water advisories: First Nations south of 60. Ottawa: Health Canada; 2017. Available: https://www.canada.ca/en/health-canada/topics/ health-environment/water-quality-health/drinking-water/advisories-first -nations-south-60.html (accessed 2017 Oct. 4).

29. a.l.l. 2003: Acceptable living level - Manitoba [report]. Winnipeg: Winnipeg Harvest \& the Social Planning Council of Winnipeg [updated 2003]. Available: http://winnipeg harvest.org/wp-content/uploads/2011/04/2003-A.L.L.-Report.pdf (accessed 2017 Apr. 19).

30. Mosby I, Galloway T. "Hunger was never absent": How residential school diets shaped current patterns of diabetes among Indigenous peoples in Canada. CMAJ 2017;189:E1043-5.

31. Bray GA, Nielsen SJ, Popkin BM. Consumption of high-fructose corn syrup in beverages may play a role in the epidemic of obesity. Am J Clin Nutr 2004;79:537-43.

\section{Competing interests: None declared.}

This article has been peer reviewed.

Affiliations: Department of Community Health Sciences (Riediger); Ongomiizwin Research (Riediger), Indigenous Institute of Health and Healing, Rady Faculty of Health Sciences; Department of Food and Human Nutritional Sciences (Riediger), Faculty of Agricultural \& Food Sciences, University of Manitoba, Winnipeg, Man.; Division of Community Health (Bombak), School of Health Sciences, Central Michigan University, Mount Pleasant, Mich.
Contributors: Both authors contributed to the conception and design of the work, drafted the manuscript, revised it critically for important intellectual content, gave final approval of the version to be published and agreed to be accountable for all aspects of the work.

Acknowledgements: We would like to thank Drs. Adriana Mudryj and Josée Lavoie, as well as the anonymous reviewers for their helpful suggestions.

Correspondence to: Natalie Riediger, Natalie.riediger@umanitoba.ca 